Revista Verde de Agroecologia e Desenvolvimento Sustentável

http://www.gvaa.com.br/revista/index.php/RVADS

ARTIGO CIENTÍFICO

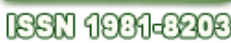

DOI: http://dx.doi.org/10.18378/rvads.v10i2.3384

\title{
Arranjos agroflorestais no contexto da agroecologia: $O$ caso dos agricultores da região do Médio Maracá no município do Mazagão, Amapá
}

\section{Agroforestry arrangements in the context of agroecology: The case of the farmers of the Middle Maracá region in the municipality of Mazagão, state Amapá}

\author{
Hilaíres Lima Maciel ${ }^{1}$; Daniel Santos de Assis ${ }^{2}$; Gilberto Ken-Iti Yokomizo ${ }^{3}$.
}

Resumo: Objetivou-se identificar localmente os diferentes arranjos, práticas e manejos agroflorestais, desenvolvidos pelos agricultores da região do Médio Maracá no município do Mazagão. Para a pesquisa foram adotadas observações diretas desenvolvida em duas etapas: a primeira constou de pesquisa e revisão bibliográficas. A segunda etapa da pesquisa foi realizada em campo. Identificou-se que as tipologias Quintal Florestal possuem área média 0,5 ha e a agrossilvicultura com área média de 5,5 ha. Quanto às espécies utilizadas o açaizeiro (Euterpe oleracea), o cupuaçuzeiro (Theobroma Grandiflorum), e a bacabeira (Oenocarpus bacaba), apresentaram maior frequência na composição dos sistemas pesquisados. Entre os lotes constatou-se uma média de 10 de espécies frutíferas por lote, quanto às essências florestais a média variou de 10 a 15 espécies. Nesta perspectiva, resgatar práticas e manejos tradicionais baseadas empiricamente nos princípios dos sistemas agroflorestais, se reveste de grande importância para apoiar implantação de sistemas produtivos com base na agroecologia.

Palavras-chave: Agroecologia, SAF, Desenvolvimento sustentável, PAE Maracá.

\begin{abstract}
Aim to locally identify the different arrangements, practices and agroforestry management practices developed by farmers of the Middle Maracá region in the city of El Jadida. For research direct observations developed in two stages were adopted: the first consisted of research and bibliographic review. The second stage of the research was carried out in the field. It was found that the Forest Yard types have average size 0.5 ha and agroforestry with an average area of 5.5 ha. As for the species used the açaí (Euterpe oleracea), the cupuaçu (Theobroma grandiflorum), and the bacabeira (Oenocarpus bacaba), had a higher frequency in the composition of the investigated systems. Among the lots found an average of 10 fruit species per lot, for the forest species the average ranged from 10 to 15 species. In this perspective, rescue traditional practices and management conditions empirically based on the principles of agroforestry, is of great importance to support implementation of productive systems based on agroecology.
\end{abstract}

Keywords: Agroecology, SAF, Sustainable Development, PAE Maracá.

\footnotetext{
*Autor para correspondência

Recebido para publicação em 07/07/2014; aprovado em 30/03/2015

${ }^{1}$ Graduado em eng ${ }^{\mathrm{a}}$ Agronômica pela Universidade Federal Rural da Amazônia - UFRA, Belém/PA, Brasil - E-mail: hlmaciel@ gmail.com

${ }^{2}$ Graduado em Administração pela Faculdade Estácio, Macapá/AP, Brasil - E-mail: assisds@ @ol.com.br

${ }^{3}$ Doutor em Agronomia (Genética e Melhoramento de Plantas) (Conceito CAPES 7). Universidade de São Paulo, USP, Brasil. Pesquisador nível III, na área de Melhoramento Genético Vegetal na Empresa Brasileira de Pesquisa Agropecuária Cpafap, EMBRAPA*, Brasil. Docente do Programa de Pós-Graduação em Desenvolvimento Regional da UNIFAP/EMBRAPA/IEPA. E-mail - gilberto_yokomizo@ yahoo.com.br
} 


\section{INTRODUÇÃO}

A agroecologia definida por Gliessman (2008) como uma prática que propõem uma nova abordagem da agricultura através da valorização, exploração e aplicação de conhecimentos e práticas conservadoras da agricultura tradicional e da aplicação de conceitos, princípios e métodos ecológicos modernos no estudo, desenho e manejo de agroecossistemas sustentáveis, tem se apresentado como uma ciência que permite juntar os conhecimentos científicos aos conhecimentos empíricos e milenares das comunidades tradicionais, agricultores familiares, extrativistas, ribeirinhos e índios acumulados durante séculos, a partir de cultivos em sistemas produtivos diversificados com uma abordagem que pode ser considerada ecológica.

Neste sentido a Agroecologia busca nortear a concepção de agricultura que se preocupa com a manutenção de um ambiente saudável com promoção de melhor qualidade de vida. Entretanto, esse é um processo que deve contar com envolvimento ativo dos povos da floresta, partindo do regate das práticas e manejos tradicionais de base ecológica dos sistemas produtivos, Agroflorestais, salvaguardando não apenas as espécies arbóreas, mas uma gama variada de grande parte das espécies cultivadas, além da cultura tradicional.

É como parte desta conjuntura que a agricultura familiar amapaense vem assentando suas bases com métodos e práticas tradicionais (extrativismo e agroextrativismo), lado a lado dos métodos modernos (agronegócio de grãos e silvicultura), num movimento permanente, desigual e combinado no tempo e no espaço como resultado do processo histórico da ocupação, formação produção e reprodução da população Amazônica e no atual cenário de crise ambiental por um lado e a pressão da racionalidade capitalista, que subordina a produção ao mercado, por outro.

A agricultura familiar, portanto, pelas suas características, por suas necessidades e por sua perspectiva econômica e social, apresenta uma tendência maior de incorporar elementos da agroecologia, porque essa seria uma forma de fazer com que sua produção seja menos dependente de capital externo, de insumos e introduzir no processo produtivo conhecimentos da agroecologia, combinando-os com conhecimentos tradicionais. Isso implicaria também em um processo de apropriação de conhecimento existente, de valorização de conhecimentos já desenvolvidos e de construção de novos conhecimentos.

Neste sentido, na busca por compreender o papel que os sistemas produtivos familiares têm cumprido na dinâmica do desenvolvimento do estado e mais importante ainda, qual papel este setor poderá cumprir no contexto da crise socioeconômica e ambiental como produtor de alimento, objetivou-se identificar localmente os diferentes arranjos, práticas e manejos agroflorestais, desenvolvidos pelos agricultores da região do Médio Maracá no município do Mazagão no estado do Amapá.

\section{MATERIAL E MÉTODOS}

A pesquisa foi desenvolvida na região denominada de Médio Maracá que faz parte do Assentamento Agroextrativista Maracá - PAE no município de Mazagão, Estado do Amapá, nas comunidades do Cafezal, São Jorge, São João e Boa Vista que estão localizadas na margem direita do Rio Preto que tem $944 \mathrm{~km}^{2}$ e corresponde a $16,54 \%$ do PAE (INCRA, 2004) (Figura 1). O acesso às comunidades é feita por via fluvial, partindo do porto do Município de Santana através do canal Norte até a foz do Rio Preto, outro acesso é pelo rio Mazagão Novo ou rio Mazagão Velho até o Rio Preto.

Para a pesquisa foram adotadas observações diretas desenvolvida em duas etapas: a primeira constou de pesquisa e revisão bibliográficas, buscando informações a respeito de Desenvolvimento Rural Sustentável, agricultura familiar e sustentabilidade, arranjos agroflorestais e sobre agroecologia, abrangendo os aspectos sociais, econômicos e ambientais que envolvem o tema. A segunda etapa da pesquisa foi realizada em campo com a aplicação de questionários semiestruturados. Este processo possibilitou a analise, composição e a dinâmica ecológica dos sistemas agroflorestais estudados, nos quais está embasada a produção agrícola das comunidades inseridas na pesquisa.

As famílias envolvidas na pesquisa foram definidas por apresentar SAF's em seus sistemas produtivos. Assim, participaram da pesquisa 17 famílias do total de 30 moradoras das comunidades de Cafezal, São Jorge, São João e Boa Vista da região do Baixo Rio Preto.

Os solos da região do Médio Maracá apresentam as seguintes características: acidez média, soma de base e teor de potássio variando de média a alta. Dosagem de fósforo baixa e saturação por bases apresenta baixo índice. A saturação de alumínio apresenta alto teor, médio teor de matéria orgânica e em relação aos aspectos granulométricos o solo no geral é considerado franco siltosa, em decorrência da deposição diária de sedimentos careados pelas marés (INCRA, 2004).

A vegetação que caracteriza a área onde a pesquisa foi realizada abrange porções de florestas de porte médio com diferenciação florística que decorre principalmente do solo e do relevo. Essa tipologia recobre de acordo com dados do INCRA (2004), 12,2\% da área total do PAE. As espécies florestais que predominam nesta área são: breu sucuruba (Tratinichia rhoifolium), quaruba-rosa (Qualea sp.), caripé (Licania spp.), faveira ou visgueiro (Parkia pendula, P. nítida, Newtonia suaveolens), muiraximbé (Emmotum fagifolium), achuá (Saccoglottis guianensis), bacaba (Oeonocarpus bacaba), morototó (Didinopanax morotottonii), tachi (Sclerollobium SP.), tapirira (Tapirira guianensis), além de outras espécies. No médio curso do Rio Preto a floresta diminui sua extensão, restringindo-se a pequena faixa ribeirinha, e ao mesmo tempo, mais pobre em diversidade e estrutura com a diminuição na ocorrência de palmeiras. 
Figura 1. Localização do Assentamento Agroextrativista Maracá - PAE no município de Mazagão no Estado do Amapá.

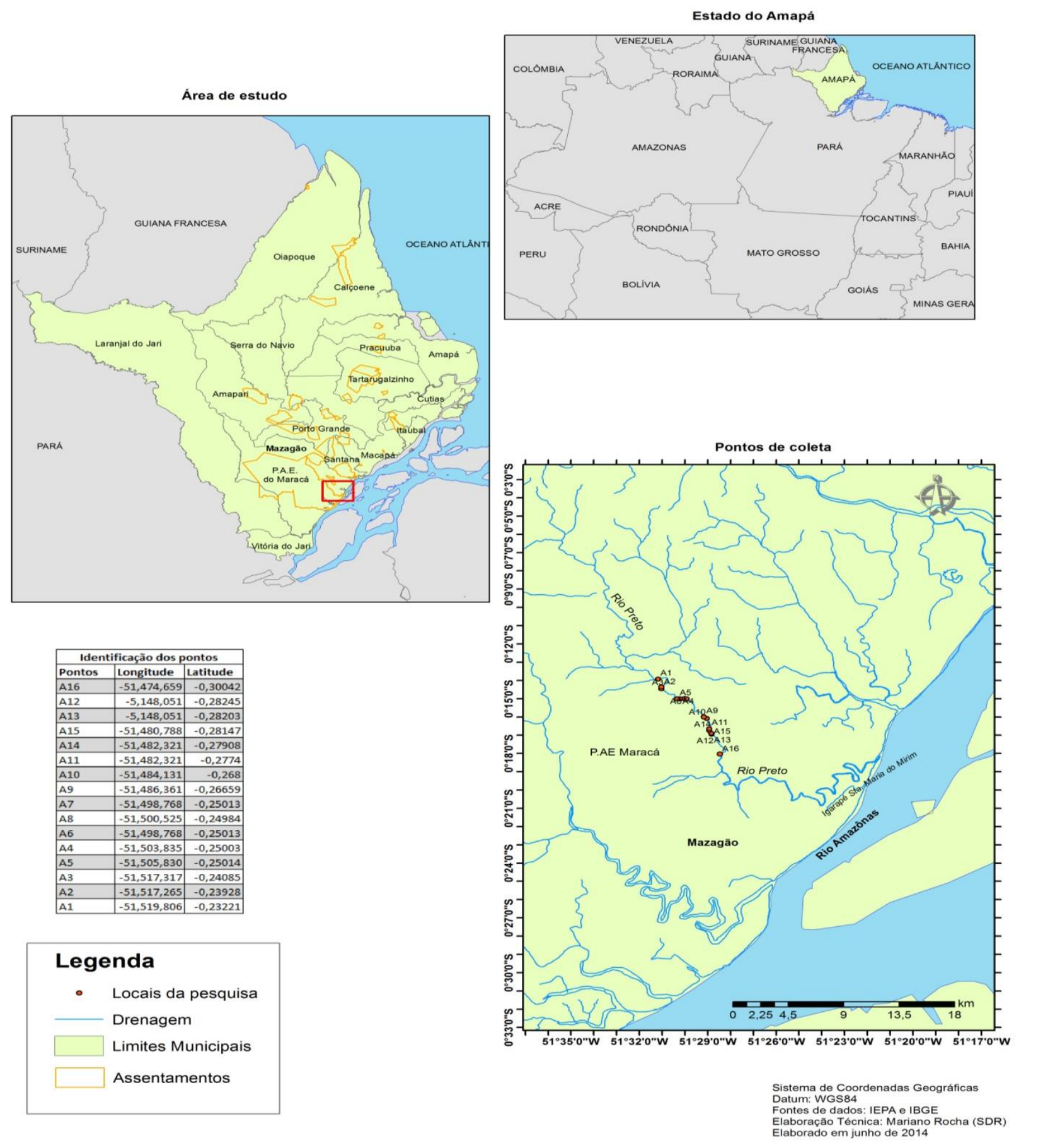

Fonte: INCRA, 2004

\section{RESULTADOS E DISCUSSÃO}

A economia das comunidades existentes da região do Médio Maracá está fundamentalmente submetida às condições ambientais tropicais, fluxos das marés, estação do ano, sazonalidade da produção e colheita dos principais produtos de sustentação da renda familiar que se junta às dinâmicas do fluxo do calendário de trabalho que força uma inevitável concorrência entre os sistemas produtivos (agricultura, extrativismo vegetal e a pesca artesanal).

Baseado nesta perspectiva identificou-se quais as variações de arranjo agroflorestal mais comumente adotado pelos agricultores. Neste sentido, verificou-se que as tipologias de quintais florestais possuem área média 0,5 ha e o da agrossilvicultura tem área média de 5,5 ha, sendo os Sistemas Agroflorestais (SAFs) observados em todos os lotes pesquisados. Quanto à composição pôde-se perceber que as culturas que presentes em todos os lotes são: o açaizeiro (Euterpe oleracea), o cupuaçuzeiro (Theobroma Grandiflorum), e a bacabeira (Oenocarpus bacaba). As outras espécies presentes são a pupunheira (Bactris gasipaes), a bananeira (Musa spp), a laranjeira (Citrus sinensis), o limoeiro (Citrus Limonium), a mangueira (Mangifera indica), o urucuzeiro (Bixa orellana), o coqueiro (Cocos nucifera), a goiabeira (Psidium guajava), a gravioleira (Anona muricata) e a aceroleira (Malpighia glabra).

Ressalta-se que as culturas do açaizero (Euterpe oleracea), do cupuaçuzeiro (Theobroma Grandiflorum), e da 
bacabeira (Oenocarpus bacaba), apresentam maior frequência na composição dos sistemas pesquisados, porque representam maior fonte de renda das famílias. Outro aspecto que contribui para a presença destas espécies nos SAF é que na região há ocorrência natural dessas espécies. Sendo que observou-se que nas áreas mais úmidas estão presente o açaizeiro e o cupuaçuzeiro.

$\mathrm{Na}$ terra firme a bacabeira compõe a vegetação nativa. Portanto, há nos SAFs uma racionalidade econômica e ecológica, buscando eficiência produtiva e ambiental, respeitando-se a adaptação ecológica de cada espécie explorada.

Nas comunidades pesquisadas observou-se uma grande variação de espécies, apesar da similaridade entre os lotes a média de espécies frutíferas foi de 10 plantas por lote, quanto as essências florestais apresentaram uma média variando de 10 a 15 espécies, encontrando-se também uma variedade significativa de espécies condimentares como as hortaliças e medicinas.

Com relação à frequência de espécies nos arranjos de SAF, de acordo com Silva (2010, p. 145), no município de São Francisco do Pará o número de espécies registradas por quintal variou entre 9 e 73 espécies, com média de 20,90 por quintal.

Nas comunidades do Médio Maracá os valores encontrados foram inferiores, no entanto, considerando o tamanho médio dos quintais que corresponde a 0,5 ha, ainda apresenta quantitativo de diversidade que permite caracterizálo dentro deste sistema. Dubois et al (1996) citam que raramente ultrapassam um hectare, entretanto têm em sua composição botânica em média 25 espécies perenes plantadas, complementação importante de alimentos e outros recursos para sua subsistência, confirmado pela pesquisa.

Figura 2. SAF composto com: Açaí, Laranja, Cupuaçu, Coco e Castanha-do-Brasil.

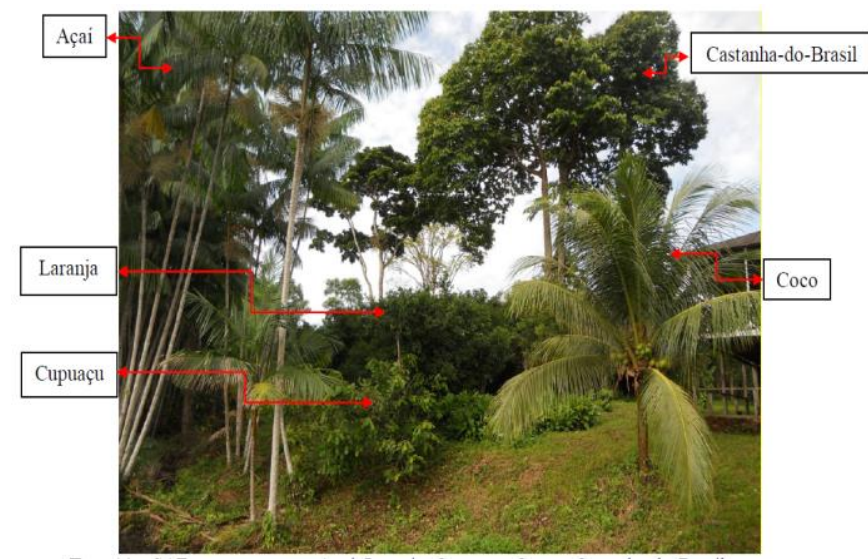

Fonte: Autor, 2015
Figura 3. SAF composto com pupunha, Graviola, Manga, Urucum e cana.

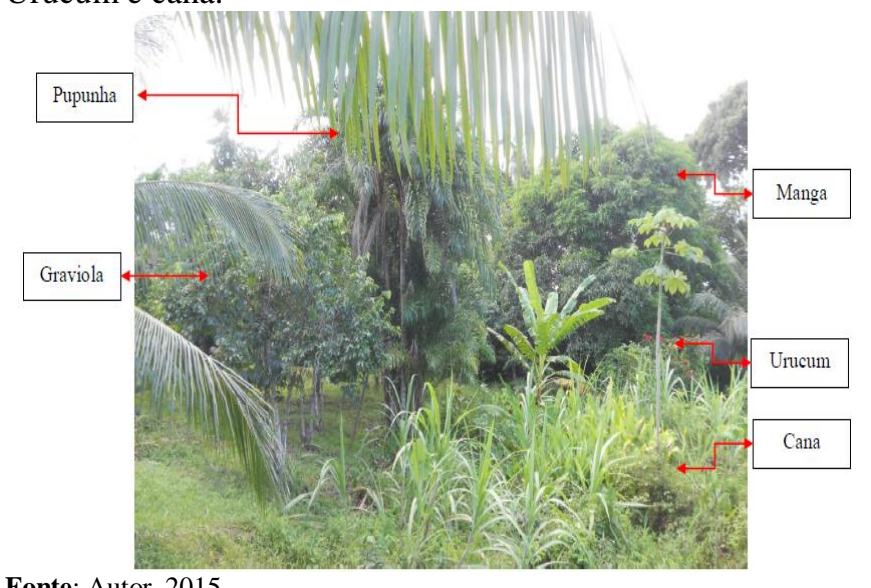

Fonte: Autor, 2015

Os sistemas produtivos desenvolvidos nas comunidades pesquisadas, geralmente conservam o máximo a natureza originária, são em pequena quantidade, as espécies vão sendo cultivadas em maior diversidade, à medida que vão se distanciando da casa em direção à mata em conjunto com as espécies nativas como: ucuúba (Virola surinamensis), taperabá (Spondias mombim), andiroba (Carapa guianensis), seringueira (Hevea brasilensis) e as espécies tipicamente de terra firme como: piquiá (Caryocar villosum), Sapucaia (Lecytis pisonis) Castanha do Brasil (Bertholletia excelsa).

As espécies frutíferas e florestais que compõe os arranjos agroflorestais na região onde a pesquisa foi realizada são definidas conforme as necessidades dos agricultores em relação à utilização no sistema produtivo. Conforme Vasconcelos (2008, p.25) "não obstante, registros na literatura que tratam da composição dos SAF mostram que em alguns casos pode ocorrer a preferência por espécies que servem para combustível, controle de erosão, melhoria do solo, forragem e postes, em detrimento de espécies frutíferas". Sempre existe a racionalidade e funcionalidade presente nas escolhas dos agricultores.

Em relação às essências florestais que compõem a estrutura do SAF observou-se que as espécies florestais são preservadas conforme os interesses dos agricultores, geralmente, devido ao potencial de utilização da espécie (Tabela 1).

Tabela 01. Critério adotado para selecionar as espécies florestais nos SAF nas cinco comunidades da região do Médio Maracá Mazagão.

\begin{tabular}{lcc}
\hline $\begin{array}{l}\text { Critério de seleção das espécies } \\
\text { florestais }\end{array}$ & Frequência & $\%$ \\
\hline Sementes/frutos silvestres & 9 & $81,82 \%$ \\
Madeira de lei & 2 & $18,18 \%$ \\
\hline Total & 11 & $100,00 \%$ \\
\hline
\end{tabular}

$\mathrm{Na}$ Tabela 2 verifica-se as espécies florestais com maior ocorrência nos lotes das famílias que participaram da pesquisa e a indicação de uso conforme informações dos agricultores. $\mathrm{O}$ que indica uma estratégia de aproveitamento sustentável de médio em longo prazo, em função do potencial de utilização apresentado pelas espécies que vai desde a madeira até a produção de óleos. 
Tabela 2. Essências florestais e a forma de utilização pelos agricultores das cincos comunidades da região do Médio Maracá Mazagão

\begin{tabular}{lcc}
\hline Nome vulgar & Nome científico & Utilização nas comunidades \\
\hline Andiroba & Carapa guianensis & Madeira para construção e extração de óleo \\
Angelim & Vatairea heteroptera & Madeira para construção \\
Ipê & Tabebuia serratifolia & Madeira para construção \\
Pau-mulato & Calycophyllum spruceanum & Madeira para construção \\
Pracaxi & Pentaclethra macroloba & Madeira para construção e extração de óleo \\
Sapucaia & Lecytis pisonis & Madeira para construção \\
Sucupira & Bowdichia nitida & Madeira para construção \\
Maçaranduba & Manilkara salzmanni & Madeira para construção \\
\hline
\end{tabular}

A pesquisa de campo também identificou que em relação à aquisição de mudas e sementes existe a preferência pela utilização de sementes e frutos silvestres como mostra a figura 4 , onde tem-se que $41,18 \%$ são obtidas de espécies silvestres existentes no lote, $29,41 \%$ são doadas, $23,53 \%$ são produzidas no lote e $5,88 \%$ das mudas e sementes são compradas, normalmente de outros agricultores da região.

De acordo com Vasconcelos (2008, p.162), no município de São Francisco do Pará 54,4\% das mudas são produzidas pelos próprios agricultores e 45,6\% são adquiridas através dos projetos financiados ou são compradas de viveiros comerciais locais ou em outros municípios. Segundo o autor é comum haver intercâmbio entre agricultores e alguns têm o hábito de guardar sementes, selecionadas por características definidas por eles, da safra anterior para serem plantadas no ano vigente. Nos dois casos verifica-se o alto grau de endogeneidade ecológica e conservação de espécies.

No caso das comunidades do Médio Maracá os resultados obtidos nas entrevistas indicam o esforço dos agricultores em desenvolver sistemas produtivos diversificados mais por necessidades e observações próprias do que por indução tecnológicas.

Figura 4. Origem das sementes e mudas utilizadas nos SAF nas cinco comunidade da região do Médio Maracá Mazagão. Estado do Amapá

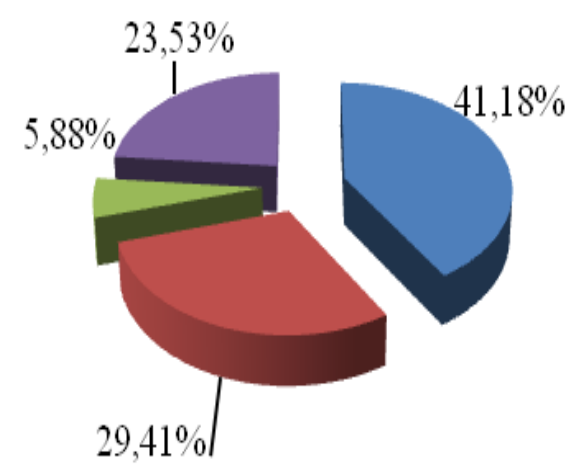

\section{Manejo dos Sistemas Produtivos}

Quanto às práticas de manejo adotadas, pelos agricultores pesquisados, a figura 5, expressa o manejo adotado se restringe a roço, poda e capina das unidades produtivas. Ressalta-se ainda que nestas comunidades a utilização de tecnologias ditas modernas como mecanização, adubação química, uso de agrotóxicos e etc. não é prática comum. Os agricultores citaram que o acesso à maioria dos lotes só é possível por via fluvial e as características ambientais da região limitam o emprego de tecnologias mais modernas como máquinas, insumos e implementos agrícolas.
Figura 5. Tratos culturais nos $\mathrm{SAF}$ realizados nos $\mathrm{SAF}$ nas cinco comunidades da região do Médio Maracá Mazagão. Estado do Amapá

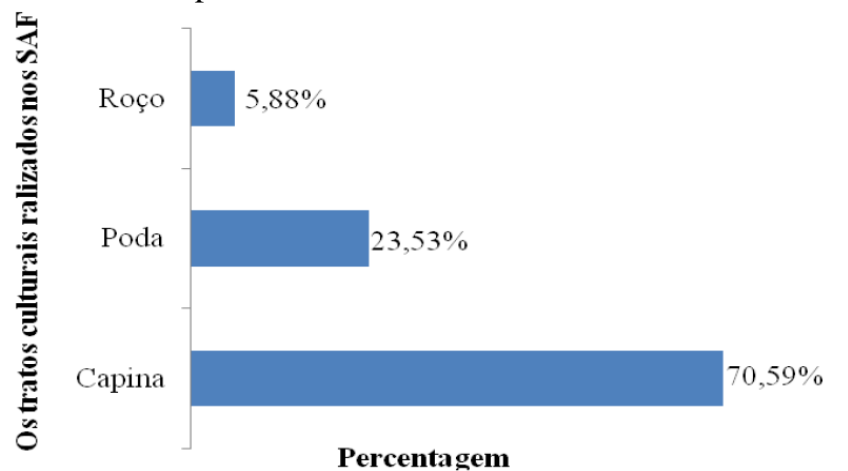

No cotidiano das atividades desenvolvidas nas unidades familiares pesquisadas verificou-se que a maioria dos agricultores conserva o método de plantio ainda comum na agricultura Amazônica, envolvendo o sistema de corte e queima e o plantio na mesma área das culturas temporárias, isso expressa uma prática que é considerada tradicional na região.

Para os agricultores que participaram da pesquisa esta estratégia permite que todas as famílias produzam e comercializem alguns produtos ao longo do ano (Figura 6). Este sistema garante uma racionalização da área utilizada e mão de obra empregada durante o ciclo dos cultivos.

Figura 6. Culturas temporárias cultivadas pelos agricultores nas cinco comunidades da região do Médio Maracá Mazagão. Estado do Amapá

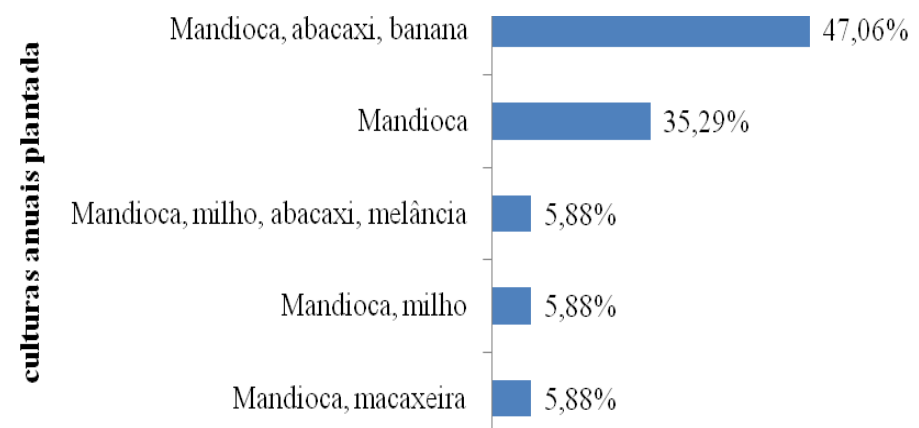

Percentual

Aspectos da Sazonalidade e da renda dos sistemas de cultivo SAF

Verificou-se com a pesquisa que os SAF são bem diversificados e são desenvolvidos sem utilização de adubação química e outros insumos externos. Nas condições 
que são desenvolvidos apresentam um grande potencial de produção durante o ciclo produtivo. Para melhor demonstrar os resultados dividiu-se em dois sistemas de cultivo, um onde estão reunidas às frutíferas perenes e extrativistas como: cupuaçuzeiro (Theobroma Grandiflorum), Castanheira-doBrasil, pupunheira, laranjeira, bacabeira e açaizeiro e o sistema de cultivo dois, que reúne as culturas temporárias: mandioqueira, bananeira e abacaxizeiro (Figuras 7 e 8). Isso garante a funcionalidade e a sustentabilidade dos sistemas desenvolvidos na região pesquisada.

Figura 7. Sazonalidade dos cultivos perenes e extrativistas nas cincos comunidades da região do Médio Maracá Mazagão. Estado do Amapá

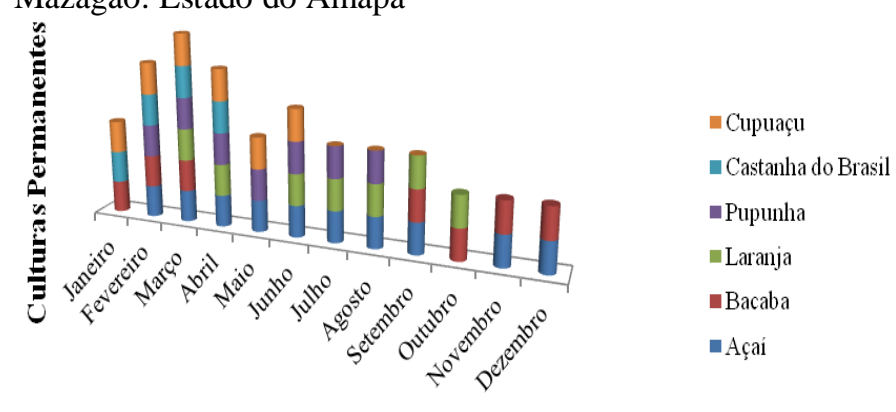

Período

$\mathrm{Na}$ análise dos dados referentes a sazonalidade dos sistemas produtivo (Figura 8) verificou-se que os agricultores conseguem ao longo de um ciclo agrícola ter uma ou mais cultura produzindo e com isso garantem alimentação e geração de renda praticamente o ano todo. Neste sentido, foi possível observar que a produção dos cultivos perenes se concentra no primeiro semestre do e a produção dos cultivos temporários no segundo semestre, o que possibilita distribuir bem ao longo do ano a força de trabalho do grupo familiar. Vale ressaltar que esse "planejamento produtivo" é inerente aos agricultores familiares, que para garantir a reprodução da família desenvolveram estratégias que historicamente tem possibilitado sua existência, cultural, social econômica e ambiental, concordando com os aspectos citados por Medeiros (2011, p.77).
Figura 8. Sazonalidade dos cultivos temporários nas cinco comunidades da região do Médio Maracá Mazagão. Estado do Amapá

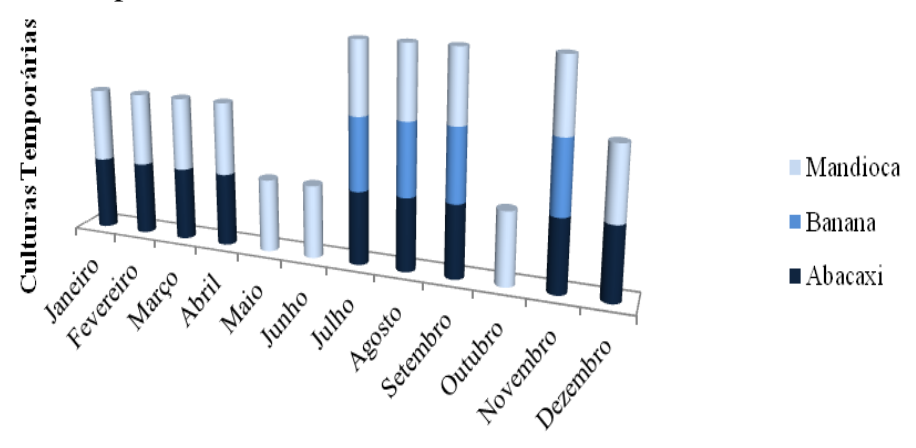

Período

Renda Bruta do sistema produtivo SAF

Parte importante da produção familiar na Amazônia se apoia em atividades extrativistas, no caso da dos agricultores da região do Médio Maracá o extrativismo do açaizero e da bacabeira são determinantes na renda das famílias. Neste sentido, a pesquisa demonstrou que mesmo nas condições de baixo investimento, tecnologia e ausência de fatores como de assistência técnica e créditos investimento e custeio a maioria dos agricultores entrevistados tem renda gerada das atividades agrícolas.

Na tabela 2 é apresentado os valores correspondentes a Renda Bruta anual (RB/a), a Renda Bruta mensal (RB/mês) gerada pelos SAF nas comunidades pesquisadas. Sendo que a média da renda bruta mensal dos SAF das comunidades do Médio Maracá é de 2,81 salários mínimos, sendo que os valores variaram de 0,49 a 10,36 SM, considerando a renda média nacional da população urbana que equivale a um salário mínimo, a maioria dos sistemas produtivos dos agricultores que participaram da pesquisa consegue obter rendas superiores à média da população urbana. Adicionalmente foi superior aos valores observados por Freitas (2008) citado por Silva (2010, p. 123) que encontrou na Ilha de Santana-AP uma média de salário bruto mensal de 1,75 SM com mínima e máxima de 0,5 SM e 4,0 SM, que naquela localidade sobrevivem quase que exclusivamente da exploração agrícola, demonstrando que os agricultores envolvidos nesta pesquisa conseguem explorar de forma mais eficientes os recursos disponíveis.

Tabela 3. Renda média mensal e Renda Bruta anual dos SAF das comunidades do Médio Maracá/Mazagão. Estado do Amapá

\begin{tabular}{lcccc}
\hline SAF & $\begin{array}{c}\text { Área média do Plantio em } \\
\text { Hectares. }\end{array}$ & $\mathrm{RB} /$ mensal $(\mathrm{R} \$)$ & $\begin{array}{c}\mathrm{RB} / \text { mensal em Salário } \\
\text { mínimo* }\end{array}$ & $\mathrm{RB} / \mathrm{anual}(\mathrm{R} \$)$ \\
\hline A1 & 4 & 572,08 & 0,84 & $6.865,00$ \\
$\mathrm{~A} 2$ & 2,5 & $1.836,67$ & 2,71 & $22.040,00$ \\
$\mathrm{~A} 3$ & 7 & 791,67 & 1,17 & $9.500,00$ \\
$\mathrm{~A} 4$ & 1,1 & 831,67 & 1,23 & $9.980,00$ \\
$\mathrm{~A} 5$ & 4 & $4.622,50$ & 6,82 & $55.470,00$ \\
A6 & 2,3 & $2.883,33$ & 4,25 & $34.600,00$ \\
A7 & 5,5 & $7.021,67$ & 10,36 & $84.260,00$ \\
A8 & 1 & 900,00 & 1,33 & $10.800,00$ \\
A9 & 1,1 & 333,33 & 0,49 & $4.000,00$ \\
A10 & 6,5 & $2.137,50$ & 3,15 & $25.650,00$ \\
A11 & 1,1 & $3.166,67$ & 4,67 & $38.000,00$ \\
A12 & 2,5 & $1.520,00$ & 2,24 & $18.240,00$ \\
A13 & 3,8 & 541,67 & 0,80 & $6.500,00$ \\
A14 & 3 & $1.400,00$ & 2,06 & $16.800,00$ \\
\hline Valores Médios & $\mathbf{3 , 2}$ & $\mathbf{1 . 9 0 3 , 9 2}$ & $\mathbf{2 , 8 1}$ & $\mathbf{2 4 . 4 7 8 , 9 3}$ \\
\hline
\end{tabular}

* O salário utilizado como referencia é o que vigorava em 2013, R\$ 678,000. 
Os valores de $\mathrm{RB} / \mathrm{mês}$ e RB/a apresentam variações que resultam do tamanho da área de plantio por ciclo agrícola e as espécies que são plantadas (Tabela 03). Sendo importante ressaltar, que a cultura da mandioca no ano agrícola de 2013 apresentou valor médio pra venda por saca de $60 \mathrm{~kg}$ de $\mathrm{R} \$$ 240,00, de acordo com informação dos agricultores entrevistados. Isto favoreceu o aumento da Renda obtida com este sistema produtivo. A pesquisa também revelou que os agricultores da Região do Médio complementam sua renda com outras atividades não agrícolas ou a partir recursos oriundos dos programas dos governos federais, estaduais e municipais. Das famílias entrevistadas $24 \%$ recebem recurso do programa Bolsa Verde, 24\% do programa Renda Viver Melhor, 59\% recebem Bolsa Família, 29\% são aposentados, $12 \%$ trabalham como diarista e $6 \%$ recebem pagamentos por serviços prestados a prefeitura por conduzir aluno.

Tabela 4. Renda média mensal e Renda Bruta anual dos sistemas produtivos de cultivos temporários das comunidades do Médio Maracá/Mazagão. Estado do Amapá

\begin{tabular}{lcccc}
\hline SPCT & $\begin{array}{c}\text { Área média do Plantio em } \\
\text { Tarefa*. }\end{array}$ & RB/mensal (R\$) & $\begin{array}{c}\text { RB/mensal em Salário } \\
\text { mínimo }\end{array}$ & RB/anual (R\$) \\
\hline $1 \mathrm{mab}^{* *}$ & 4 & $1.581,67$ & 2,33 & $18.980,00$ \\
$2 \mathrm{mb}^{* * *}$ & 2 & $1.108,33$ & 1,63 & $13.300,00$ \\
$3 \mathrm{mb}$ & 6 & $2.608,33$ & 3,85 & $31.300,00$ \\
$4 \mathrm{mab}$ & 6 & $2.341,67$ & 3,45 & $28.100,00$ \\
$5 \mathrm{mab}$ & 3 & 845,83 & 1,25 & $10.150,00$ \\
$6 \mathrm{mab}$ & 4 & $1.153,33$ & 1,70 & $13.840,00$ \\
$7 \mathrm{ma}$ & 8 & $1.004,16$ & 1,48 & $12.050,00$ \\
$8 \mathrm{ma}$ & 2 & 350,00 & $4.200,00$ \\
$9 \mathrm{ma}$ & 2 & 350,00 & 0,52 & $4.200,00$ \\
$10 \mathrm{mab}$ & 2 & 960,00 & 0,52 & $11.520,00$ \\
$11 \mathrm{ma}$ & 2 & 160,00 & 1,42 & $1.920,00$ \\
$12 \mathrm{~m} * * * *$ & 2 & 137,50 & 0,24 & $1.650,00$ \\
$13 \mathrm{mab}$ & 12 & $2.333,33$ & 0,20 & $28.000,00$ \\
$14 \mathrm{ma}$ & 12 & 933,33 & 3,44 & $11.200,00$ \\
$15 \mathrm{mab}$ & 2 & 451,21 & 1,38 & $5.414,50$ \\
\hline Valores médios & $\mathbf{4 , 6}$ & $\mathbf{1 . 0 8 7 , 9 1}$ & 0,67 & $\mathbf{1 3 . 0 5 4 , 9 7}$ \\
\hline * & & & $\mathbf{1 , 6 0}$ & \\
\hline
\end{tabular}

* corresponde a uma área de 55x55m.

** mandioca, abacaxi e banana; *** mandioca e banana; ****mandioca.

\section{CONCLUSÕES}

Os agricultores da região do Médio Maracá desenvolvem estratégias que tem possibilitado sua permanência nos seus lotes. Os sistemas produtivos são diversificados o que garante as famílias produção ao longo do ano.

A região do Médio Maracá, no Projeto de Assentamento Agroextrativista do Maracá guarda um potencial produtivo que precisa ser fomentado por políticas públicas, que possibilite aprimoramento dos sistemas desenvolvidos por esses agricultores, baseado em Sistemas Agroflorestais, como sistema produtivo e a Agroecologia com ciência se constitui uma alternativa, com seu instrumental teórico-prático para o desenvolvimento de sistemas de produção de alimentos, conservação ambiental e reprodução social numa perspectiva de sustentabilidade em longo prazo.

\section{REFERÊNCIAS}

DUBOIS, J. C. L. VIANA, V. M. ANDERSON, A. Manual agroflorestal para a Amazônia. Rio de Janeiro: REBRAF. 1996.

GLIESSMAN, S. R. Agroecologia: processos ecológicos em agricultura sustentável. 4 ed. - Porto Alegre: Editora da UFRGS, 2008.

IAMAMOTO, André. Agroecologia e Desenvolvimento Rural, 2005.In: http://www.agroecologia.pro.br/arquivos/agroecologia/teses/d issertacao_agroecologia_esalq.pdf. Acesso em: 11/03/2013.

INCRA. Plano de Desenvolvimento do Projeto de Assentamento Extrativista do Maracá. Amapá, 2004.

MEDEIROS, C. A. B. Transição agroecológica: construção participativa do conhecimento para a sustentabilidade resultados de atividades 2009|2010 / Editado por Carlos Alberto Barbosa Medeiros, Flávio Luiz Carpena Carvalho, André Samuel Strassburger - Brasília, DF: Embrapa, 2011.

SILVA, R. B. L. e. Diversidade, uso e manejo de quintais agroflorestais no Distrito do Carvão, Mazagão-AP, Brasil. Tese (Doutorado) -Universidade Federal do Pará, Núcleo de Altos Estudos Amazônicos, Programa de Pós-Graduação em Desenvolvimento Sustentável do Trópico Úmido, Belém, 2010 .

VASCONCELOS, P. C. S. Os sistemas agroflorestais de agricultores familiares do município de São Francisco do Pará: principais barreiras e oportunidades. Tese (Doutorado) Universidade Federal Rural da Amazônia - UFRA, Curso de Ciências Agrárias, área de concentração em Agroecossistemas. Belém 2008. 